\title{
Investigating the lagged effect of weather parameters on travel time reliability
}

\author{
M. Mesbah ${ }^{1}$, M. Luy ${ }^{1} \&$ G. Currie ${ }^{2}$ \\ ${ }^{1}$ School of Civil Engineering, University of Queensland, Australia \\ ${ }^{2}$ Department of Civil Engineering, Monash University, Australia
}

\begin{abstract}
Travel time reliability is affected by a range of factors including traffic demand, road infrastructure, accidents, and weather. Although the effect of weather conditions on travel time reliability has been extensively studied, the majority of studies focus on the weather parameters during a trip. However, passengers may decide on their trip attribute (e.g. trip start time and travel mode) based on the weather conditions before the trip. Alternatively, passengers may decide based on weather predictions for the entire day and not just the weather during the morning travel. This paper aims to explore the effect of weather parameters with a lead (before starting a trip) or a lag (after an urban trip is completed). For this purpose Automatic Vehicle Location (AVL) data in Melbourne, Australia was used. This large dataset included all tram movements for more than ten routes in a period of five years during the morning peak. The results indicate that precipitation (rainfall) is the most important weather parameter to affect travel time reliability and precipitation during the trip is the most significant period followed by the rain during the last hour of the morning peak. This suggests that considering a lag in weather parameters may increase the accuracy of travel time reliability estimations.
\end{abstract}

Keywords: transit reliability, rain, big data.

\section{Introduction}

Travel time reliability is perceived as important as travel time itself by public transport passengers [1]. Reliability measures are also used as a performance measure by public transport authorities to evaluate the performance of operators. A range of parameters affect travel time reliability which can be classified into 
planned and unplanned events. The planned events include scheduled road maintenance or upgrades and a special event such as a major sports match. Unplanned events include traffic incidents, adverse weather conditions, and extreme natural hazards. Other transit system properties that can affect reliability could be referred to as demand fluctuations, general traffic congestion among others $[2,3]$. Although transit travel time reliability has been extensively studied in the literature and many of the affecting parameters on reliability have already been identified, there has been limited attention to the lagged effect of weather on reliability. It should be noted that the effect of weather parameters such as rain and temperature during the travel period have been explored; but the effect of weather conditions before and after the travel period is yet to be determined.

Kwon et al. [3] found that during the morning peak, the majoritity of unreliability was a result of congestion. On average, weather contributed up to five percent to travel time unreliability. Acoording to Mazloumi et al. [4] rainfall was only a significant factor during the AM (morning) peak, where congestion was a factor. In other periods, the rainfall effect was not significant. Guo et al. [5] intuitively chose some variables to represent weather such as a dummy variable for 'heavy rain'. The effect of unreliability on passenger demand is investigated by van Oort et al. [6].

AVL data have facilitated travel time studies around the world by recording and archiving data at a very low cost [7]. El-Geneidy et al. [8] remarked on the importance of AVL on enhancing services quality, pointing out the increasing usage of AVL systems by transit agencies in the US. Moreover, Hounsell et al. [9] state that the future will probably see an increase in AVL transit systems.

The lagged effect of weather is not considered in the literature. The weather conditions during the trip affect travel time and travel time reliability by affecting demand and supply. Moreover, the weather conditions before a journey starts can potentially affect both demand and supply. Passengers make decisions on the mode of their trips before starting it in the morning. This could simply be done by looking out of the window and deciding how to travel for the day. Passengers with more than one option (e.g. leaving home earlier or later for work or using a private car or public transport) may change their travel start time (or travel mode) on a rainy day. If the majority of passengers choose to drive on rainy days, there will be more traffic congestion observed on the road network. Consequently, public transport vehicles sharing the roads will also suffer. On the other hand, when the majority choose to drive, public transport demand decreases which can potentially improve public transport performance.

The lagged effect could also be attributed to weather conditions during the day and after the morning trip is completed. The hypothesis here is that the passengers may seek the (correct) weather prediction to make a decision for their mode of travel. The weather conditions after the morning peak is important since the commuters are expected to make decisions for both their 'to work' and 'to home' decisions simultaneously. If the weather forecast is normal conditions for morning but heavy rain for the afternoon, the non-captive passengers, who would like to drive when raining, will also choose car for the morning trip. This paper investigates the effect of weather both prior and after the morning trip. 
The rest of this paper is structured as follows: The next section discusses the data used for the analysis which is followed by the statistical analysis of travel time reliability. Then the results are discussed and the conclusions are presented.

\section{Melbourne tram data}

Two datasets are prepared and merged for this analysis, namely the Automatic Vehicle Location (AVL) system and weather observation data. The Melbourne tram network utilizes an AVL system to record information such actual time of arrival and departure to every stop, scheduled time of arrival and departure, time stamp, and vehicle ID. This information is archived for the past 15 years by the operator (Yarra Trams) [10]. One of Melbourne's AVL advantages is recording the historical schedule times as well as the actual travel times. This provides an opportunity to compare the tram performance with its schedule at the time.

The second dataset used was the weather observations from three weather stations in Melbourne. The minute by minute weather observation data was collected from Melbourne Airport (Station 086282), Moorabbin Airport (Station 086077), and Melbourne CBD (Station 086071) through the Australian Department of Meteorology.

A very large dataset of tram AVL is used in the present study which includes all trips of ten radial routes in 2006 to 2010 inclusive. Studied routes are Route 1, 3, 8, 19, 59, 64, 86, 96, 109 and 112 traveling between Melbourne suburbs and the Central Business District (CBD). Since all routes run radially to the CBD, the load profile and congestions effects are expected to be similar [11].

Using the travel time between each timing point, a representative total travel time was calculated for the route. This was undertaken by adding travel time between the second stop to the second-last stop for each journey. This is because a large variability was observed in the first and the last stop. Further details on this assumption are available in Mesbah et al. [12].

This study focuses on the morning peak (7-9 am). There are a total of 217,781 individual tram trips in the data base for all ten tram routes in the duration of five years between 2006 and 2010 .

\section{Statistical analysis}

A statistical analysis is presented in this section to evaluate the lagged effect of weather on transit reliability. The aim is to evaluate the effect of one parameter by a factor analysis not to develop a model to predict transit reliability. The period of rain is the independent parameter the effect of which is evaluated and the dependent variable is a measure of reliability.

A regression analysis with the dependent variable of travel time and a set of independent variables shows how much of the variation in travel time is attributed to each of the independent variables. Two conventional measures to determine the significance of an independent variable in predicting a dependent variable are the goodness of fit and coefficient significance (hypothesis testing that the coefficients of the dependent variables are different from zero). The goodness of 
fit is checked by the $\mathrm{R}^{2}$ value and F-test and the coefficient significance by the Student's t-test.

The dependent variable is travel time in this study and the majority of its variation can be explained by the tram schedule. This is expected for a public transport service since the tram drivers try to match the schedule and not just to arrive as fast as possible. The generic form of a regression model to undertake this factor analysis is as follows:

$$
\mathrm{t}_{\text {actual }}=\beta_{0}+\beta_{1} * \mathrm{t}_{\mathrm{sch}}+\beta_{2} * \mathrm{~W}+\varepsilon
$$

where:

$t_{\text {actual }}$ : the actual travel run time (observed).

$t_{\text {schedule }}: \quad$ the schedule travel time.

$W: \quad$ the weather parameter.

$\beta_{i}: \quad$ the coefficient associated to the variable $i$.

$\varepsilon: \quad$ the error term.

The available weather parameters is a long list including precipitation, wet bulb temperature, wind speed, wind direction, dew point temperature, relative humidity (percentage), maximum wind gust in last 10 minutes, and mean sea level pressure. Lin (2013) showed that precipitation is by far the most important weather parameter; hence this study will focus only on the lagging effect of precipitation. Table 1 describes the alternative precipitation variables considered in this analysis. It should be noted that only one of the variables in Table 1 will be used instead of $\mathrm{W}$ in Equation 1 since these variables are expected to have a higher correlation and they should not be included in a model simultaneously.

Table 1: Weather variables.

\begin{tabular}{|l|l|l|}
\hline Variable Name & Description & Duration \\
\hline Precip7_9 & $\begin{array}{l}\text { Precipitation from 7 am to 9 am (in mm) } \\
\text { - Morning Peak }\end{array}$ & 2 hours \\
\hline Precip6_8 & $\begin{array}{l}\text { Precipitation from 6 am to 8 am (in mm) } \\
\text { - One hour shift to morning peak }\end{array}$ & 2 hours \\
\hline Precip6_7 & Precipitation from 6 am to 7 am (in mm) & 1 hour \\
\hline Precip7_8 & Precipitation from 7 am to 8 am (in mm) & 1 hour \\
\hline Precip8_9 & Precipitation from 8 am to 9 am (in mm) & 1 hour \\
\hline Precip9_10 & Precipitation from 9 am to 10 am (in mm) & 1 hour \\
\hline Precip10_11 & $\begin{array}{l}\text { Precipitation from 10 am to 11 am (in } \\
\text { mm) }\end{array}$ & 1 hour \\
\hline Precip9_5 & $\begin{array}{l}\text { Precipitation from 9 am to 5 pm (in mm) } \\
\text { - Normal working hours }\end{array}$ & 8 hours \\
\hline Precip8_6 & $\begin{array}{l}\text { Precipitation from 10 am to 11 am } \\
\text { (in mm) } \\
\text { - One hour before and after the normal } \\
\text { working hours }\end{array}$ & 10 hours \\
\hline
\end{tabular}


The aim is now to determine which of the variables tabulated above has the highest significance in determining tram travel times. Figure 1 demonstrates the change in goodness of fit $\left(\mathrm{R}^{2}\right.$ and $\mathrm{F}$ value) and coefficient significance $(\mathrm{t}$ value). The $t$ value and $R^{2}$ are shown on the left axis and $F$ value on the right axis. Overall, the change in $t$ value follows the same trend as the $F$ value which indicates that the important variables in terms of goodness of fit are consistent with the coefficient significance criterion. It can be observed that the precipitation during the morning peak (Precip7_9) has the highest $t$ value and F value and thus is the best variable to represent precipitation. Shifting this to one hour earlier (Precip6_8) decreases $t$ value and $F$ value.

Considering one hour variables (Precip6_7, Precip7_8, Precip8_9, Precip9_10, Precip10_11), precipitations at the end of the peak period (Precip8 9) is the most significant variable with very close $t$ value and $F$ values to Precip7 9 (the precipitation variable with no shift). This suggests that for trips made in 7-8 am and 8-9 am, the one hour precipitation in 8-9 am (Precip8_9) is as important as the two hour precipitation in 7-9 am (Precip7 9). Therefore there may be worth considering a lagged effect of weather during the peak hour. This again suggests that precipitation during the travel period (morning peak) is the most important variable compared to leading or lagging periods.

The last segment of Figure 1 shows the precipitation during the working hours and beyond (Precip9_5 and Precip8_6). These variables take into account the behaviour of looking at the weather forecast before deciding on a daily commute. These periods have a considerably less significance in comparison to Precip7_9, reconfirming that the precipitation during the travel period is more significant than any other period.

All models have similar $\mathrm{R}^{2}$ and $\mathrm{F}$ values since scheduled travel time is included in the model (Equation 1) as the most important parameter explaining about $95 \%$ of the variation in travel time.

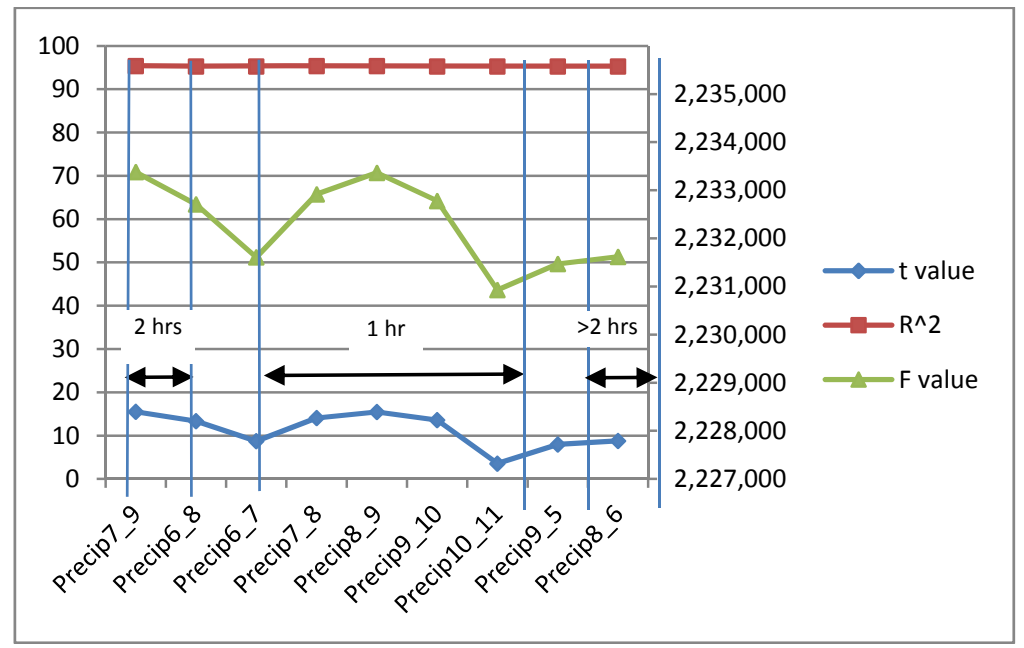

Figure 1: Change of $\mathrm{T}$ value, $\mathrm{R} 2$, and $\mathrm{F}$ value with precipitation variables. 
The analysis above was carried out on travel time during the two hours morning peak period (7-9 am). In another analysis the peak hour was divided into two one hour periods (7-8 and 8-9 am). Repeating the above analysis on one hour travel time values, results in a similar trend to the trend of Figure 1. This indicates that the precipitation during the travel period is of the highest significance.

\section{Conclusions}

The effect of weather on public transport travel times has been extensively explored in the literature. However, there is little evidence on the effect of weather in the leading or lagging periods of travel. This paper investigates the effect of weather conditions prior to making a public transport trip and also after the trip. The analysis was undertaken on five years of Automatic Vehicle Location (AVL) data collected from ten tram routes in Melbourne, Australia. The travel time during the morning peak was extracted for this analysis. Following the emphasis on the effect of rain on travel time reliability, precipitation was chosen as a proxy for weather conditions.

A statistical analysis of these periods is presented using goodness of fit and coefficient significance measures. Comparing the leading and lagging weather observations with the 'during the trip' observations reveals that weather conditions during the travel period is the most important variable.

\section{References}

[1] J. Bates, J. Polak, P. Jones, and A. Cook, "The valuation of reliability for personal travel," Transportation Research Part E, vol. 37, pp. 191-229, 2001.

[2] Federal Highway Administration. (2009, 29 August). Travel Time Reliability - Making It There On Time, All the Time. Available: http://www.ops.fhwa.dot.gov/publications/tt_reliability/TTR_Report.htm

[3] J. Kwon, T. Barkley, R. Hranac, K. Petty, and N. Compin, "Decomposition of Travel Time Relibability into Various Sources - Incidents, Weather, Work Zones, Special Events, and Base Capacity," Transportation Research Record: Journal of the Transportation Research Board, pp. 28-33, September 2011.

[4] E. Mazloumi, G. Currie, and G. Rose, "Using GPS Data to Gain Insight into Public Transport Travel Time Reliability," Journal of Transportation Engineering, pp. 623-631, July 2010.

[5] Z. Guo, N. H. M. Wilson, and A. Rabhee, "Impact of Weather on Transit Ridership in Chicago, Illinois," Transportation Research Record: Journal of the Transportation Research Board, pp. 3-10, 2007.

[6] N. van Oort, T. Brands, E. de Romph, and J. Aceves Flores, "Incorporating Unreliability of Transit in Transport Demand Models: Theoretical and Practical Approach," in 93rd Transportation Research Board Meeting, 2014, p. 15. 
[7] D. Paliska and J. Kolenc, "Analysis of bus service reliability using AVL data: Case study of the City of Koper," Promet - Traffic-Traffico, vol. 20, pp. 113-118, 2008.

[8] A. M. El-Geneidy, J. Horning, and K. J. Krizek, "Analyzing transit service reliability using detailed data from automatic vehicular locator systems," Journal of Advanced Transportation, vol. 45, pp. 66-79, 2011.

[9] N. B. Hounsell, B. P. Shrestha, and A. Wong, "Data management and applications in a world-leading bus fleet," Transportation Research Part C: Emerging Technologies, vol. 22, pp. 76-87, 2012.

[10] G. Currie and M. Mesbah, "Visualization of Geographical Information System and Automatic Vehicle Location Data to Explore Transit Performance," Transportation Research Record: Journal of the Transportation Research Board, vol. 2216, pp. 59-66, 2011.

[11] M. Mesbah, G. Currie, C. Lennon, and T. Northcott, "Spatial and temporal visualization of transit operations performance data at a network level," Journal of Transport Geography, vol. 25, pp. 15-26, 2012.

[12] M. Mesbah, G. Currie, and N. Peñafiel Prohens, "The Effect of Daylight on Reliability of Transit Service: Case Study of the Melbourne Tram Network," in 93rd Transportation Research Board Meeting, 2014, p. 11. 